\title{
Clearing up “Critical Thinking”: Its Four Formidable Features
}

\author{
Merinda Bermingham \\ Faculty of Education, Monash University, Melbourne, Australia \\ Email: Merinda.Bermingham@gmail.com
}

Received 2 March 2015; accepted 20 March 2015; published 24 March 2015

Copyright (C) 2015 by author and Scientific Research Publishing Inc.

This work is licensed under the Creative Commons Attribution International License (CC BY). http://creativecommons.org/licenses/by/4.0/

(c) $\underset{\mathrm{EY}}{\mathrm{i}}$ Open Access

\begin{abstract}
In this article, I identify four key features of critical thinking that draw together threads of research in this area for clarification for teachers. These four features comprise skills and dispositions required to operate in combination to achieve critical thought. In light of their challenging nature-challenging to develop and challenging to perform-I have called them formidable. I argue that we need a significant emphasis on the dispositions encompassed by genuinely critical thought, since a skills-based understanding neglects the importance of its inherent critical dimension. I seek to emphasize the importance of students' ability and willingness to: reflect metacognitively, become increasingly aware of socio-cultural power structures at play on their thinking, and contribute to the common good, in addition to the higher order thinking and logical reasoning involved. These skills and dispositions are required in the development of students capable of, and likely to engage in, critical thinking within and beyond their formal education.
\end{abstract}

\section{Keywords}

Critical Thinking, Thinking Critically, Thinking Skills, Dispositions, Moral Issues in Critical Thinking

\section{Introduction}

Education is good just so far as it produces a critical faculty (Sumner, 1906: p. 1564).

An understanding of the value of critical thinking is long established and educational policy makers articulating goals for education in the 21 st century recognize its prevailing importance. A clarified understanding of critical thinking among school teachers may help contribute to a more explicit focus on critical thinking in the classroom. In this article, I identify four key features of critical thinking that draw together threads of research in this area for clarification for teachers (Table 1). These four features include an ability and willingness to: reason logi- 
cally, reflect metacognitively, become increasingly aware of socio-cultural power structures at play on thinking, and to contribute to the common good. In light of their challenging nature - challenging to develop and challenging to perform-I have called them formidable. I argue that we need a significant emphasis on the dispositions encompassed by genuinely critical thought, since a skills-based understanding neglects the importance of its inherent critical dimension. These skills and dispositions are required in the development of students capable of, and likely to engage in, critical thinking within and beyond their formal education. I have endeavored to communicate such an understanding in this paper, since it has been some time since there has been a clarified conception, and since it is incumbent upon all educators to clearly grasp this important learning outcome, one that traverses discrete subject disciplines.

\section{Four Formidable Features}

\subsection{Logical Reasoning}

A person engaged in critical thinking uses a core set of cognitive skills-analysis, interpretation, inference, explanation, evaluation, and self-regulation - to form judgments (Facione, 1995: p. 3).

It seems tautological that in order to think critically we require the skill to do so first and foremost. There is considerable agreement among experts that critical thinking includes skills in applying, analysing, and evaluating information (Ruminski \& Hanks, 1995: p. 3). Critical thinking is thus associated with higher order thinking skills (Bloom, 1956) that facilitate the logical reasoning required. When Lipman (1988: p. 40) examines the "defining features" of critical thinking, he emphasizes its criterological nature and ensuing dependence upon "good thinking" involving the identification and citing of "good reasons". Through his prioritising of a logical approach and well-defended thinking he comes to describe critical thought as "a sort of cognitive accountability" (1988: p. 40). In this way, critical thought is "accountable" to reasons and evidence that justifiably lead to conclusions. Lipman's (1984: p. 52) emphasis on "reasoning abilities" and our need "to consider evidence" is shared among researchers, including Facione (1990) who informs that critical thinking is "trustful of reason" (1990: p. 2). Facione emphasizes our need to explain "evidential... considerations upon which (our) judgments are based".

\section{Table 1. Critical thinking: four formidable features.}

\section{Logical reasoning:}

Critical thinkers are concerned with the ability to evidence claims in a valid and sound manner

- An ability and willingness to think logically; to defend and form perspectives without contradiction, a willingness to accept or reject ideas based on evidence

- An ability and willingness to identify, challenge and analyse assumptions for validity, an ability to independently examine knowledge and opinions to solve problems

Reflection and open-mindedness:

Critical thinkers reflect metacognitively, purposefully and open-mindedly

- An ability and willingness to reflect meaningfully; to think about one's own thinking metacognitively; to engage in purposeful and honest self-reflection in a manner that requires logic, a propensity to engage in an activity with reflective scepticism

- An ability and willingness to suspend judgment

- A willingness to be open-minded so that perspectives can shift in light of new evidence

- An ability and willingness to be self-regulative; to have no bias toward one's own perspectives ipso facto, to engage in a purposeful analysis of one's own judgments

An awareness of the power relationships that influence thinking:

Critical thinkers strive toward an increasingly conscious appreciation of the constructed nature of our thinking and influences of power structures

- An ability and willingness to appreciate, understand and examine the complex interplay of experiences and power relationships that influence our perceptions and thinking; to appreciate the constructed nature of our all our thinking

Striving toward the common good:

Critical thinkers are inspired by a willingness to seek the truth for productive ends

- An ability and willingness to accept that all ideas demand scrutiny; a willingness to continually critique ideas in appreciation of the need to seek truth and strive to achieve productive ends, which inevitably develops resilience, inquisitiveness and an innovative drive toward the common good 
When one thinks critically, part of what they do is to use "use reason, rather than some other strategy to address serious problems" (Facione et al., 1995: p. 7). There is a general consensus that logical reasoning occupies a foremost place in critical thinking (Robinson, 2011; Ruminski \& Hanks, 1995). Thus the competent critical thinker has "a zealous dedication to reason, and a hunger or eagerness for reliable information" (Facione, 2013: p. 10).

Reasoning skills of the highest order are imperative in the critical thinker, but not ipso facto. Indeed, reasoning skills warranting the descriptor critical, do so because of the depth, complexity and honesty with which they are performed. That is to say that not all logical reasoning comprises critical thought. Indeed the critical nature of the reasoning entailed is achieved through dispositions or inclinations, even intentions, which give weight to the contexts, motives and power structures that influence our thinking processes. So what specifically might teachers and their students need in order to navigate their way from learning to reason logically, valuing evidence and seeking evidence to substantiate their views, which will give way to the genuinely critical thought that teachers endeavour to inspire in students?

\subsection{Honesty, Open-Mindedness and Reflection}

As water strengthens a thirsty planet, the affective dispositions are necessary for critical thinking skills... to take root and flourish in students (Facione, 1990: p. 11).

The way we perform our reasoning demands a level of honesty facilitated by an open-minded and reflective approach. A seminal researcher in this area, Ennis' appreciation of the logical thinking component of critical thinking is contextualized by the requirement of honesty, since it is possible to manipulate rules of logic in a sophistic manner that is closer to rationalizing than rational thought (by sophistic I refer to a manipulation of reasoning that is self-serving or used to justify pre-conceived conclusions, consciously or unconsciously). Critical thinking thus demands the "honest representation of intellectual opinions" (Ennis, 1996: p. 9). When Facione (1990: p. 2) contextualizes his understanding by describing our critical judgments as "purposeful" and "selfregulatory", he moves beyond higher-order thinking skills to acknowledge a need to regulate thinking so that it is motivated toward truth-seeking and an individual's premises are not accepted ipso facto, or after a judgment has already been formed. For Facione, all contributions to arguments are regulated when we think critically, regardless of whose they are. Acknowledging a relationship between evidence and our conclusions matters, but without some open-minded consideration given to the nature of the evidence accessed, and the context of the thinker, we can slip into rationalizing without conscious awareness of the constructed nature of our thinking that lies at the heart of the point of critical thought.

In order to avoid sophistry or rationalization, and to ensure our logical reasoning capacities are used in an honest manner consistent with their utmost potential, teachers will require of their students a keen emphasis on reflection and metacognition. This can help to overcome these all-too-common tendencies that inevitably slip into the habits of our everyday thinking. Open-mindedness allows critical thinking to be "self-correcting" (Lipman, 1988: p. 41). This is because rather than insisting on our own perspectives, an open-minded thinker is willing to critically and continually assess their views and how they have come about. No wonder "most debates around critical thinking tend to stress... a skeptical, reasonable, and reflective approach" (Mason, 2007: p. 344). The skepticism that can ensue from open-mindedness means all ideas, irrespective of whose they are, may be scrutinized. Hence there is an inherent connection between open-mindedness and self-reflection, since the former disposition encourages the latter outcome. The same can be said for inquisitiveness, another disposition that inspires reflection and alerts people to opportunities to think critically (Facione, 2013). These dispositions also mean that critical thinking inspires a (concernedly rare) "willingness to suspend judgement" (Verlinden, 2005: p. 24) and openness to having one's mind changed in light of new evidence (Bassham et al., 2005: p. 3). This latter outcome reiterates the benefit of open-mindedness when such an approach is adopted in conjunction with logical reasoning. Critical thinking "entails rigorous self-reflection and open-mindedness" (The Center for Critical Thinking, 2013) because these propensities are imperative to ensuring a critical approach toward belief construction, and our seeking and acquiring evidence. Further, these features of critical thought facilitate our potential to consciously consider the impact of cultural, political and economic forces at play on our access to and interpretation of evidence.

\subsection{An Awareness of Power Relationships That Impact Our Thinking}

Critical thinking skills and abilities (are) essential to the free, rational and autonomous mind (Paul \& Binkler, 
1990: p. 163).

An open-minded and reflective approach to our logical reasoning nurtures another disposition equally important to critical thinking. Although some discourse in this area distinguishes critical thinking from thinking critically, which is more readily associated with being aware of complex interplays of experiences, relationships and power structures on one's thinking (phenomena explored in critical theory), most researchers identify this awareness as encompassed by critical thinking. I argue that an ability and willingness to become increasingly conscious of the range of influences in social and academic worlds that impact the nature and caliber of our thinking go hand-in-hand with reflection and open-mindedness. Consider that when we reflect on our thinking, we should consider what is influencing it, why it takes the shape it does, why we think we know what we know, what understandings and knowledge we might be missing. And it is through being open-minded that we are enabled to seek potential answers to metacognitive questions like these in an honest manner and in a manner that will inevitably lead to observations about the impact of our cultures, politics and economics.

Lipman (1984: p. 53) identifies "assumptions" pertaining to the value of critical thinking that are incorporated in his programs for teaching: "Children should learn to think for themselves", he insists, "to explore alternatives to their own points of view... to make careful distinctions and to become aware of the objectives of the educational process". An awareness of such objectives speaks to the development of an ability to become aware of contextual considerations and power relationships that impact our thinking. In learning to "think for themselves" and "explore alternative" points of view, Lipman speaks to skills and dispositions that encourage students to reflect on their own perspectives in relation to the views and influences that surround them. The importance of honesty too is entwined with considerations of power since it is required in order to "face one's own biases, prejudices... egocentric or sociocentric tendencies" (Facione, 1990: p. 13) as instilled in us by our context and culture, and which impede the kind of free, rational thought Paul \& Binkler (1990) critical thinking works to promote. But being aware in this way requires a capacity to, and willingness to, reflect in a purposeful and open-minded manner.

\subsection{A Moral Underpinning}

In my education, as in that of everyone, the moral influences... are so much more important than all the others... (Mill, 1873: p. 52).

Finally, there exists a less talked about but equally important feature of critical thought that underpins its function. Consider why it is that we do not assume someone seeking reasons to justify pre-conceived ideas as someone who is engaging in genuinely critical thought. Such a person would not be considering all the available evidence, nor reflecting on what influences have come to impose themselves on their pre-conceived understanding, and so not being critical. These things are all true, but at the heart of this kind of thinking, what bothers me is that the person is thinking in accordance with their own pre-conceived ideas and interests. The intuition that this self-interested approach is problematic, and its disqualification from status as critical thought as we understand it, helps reveal that there must be a moral underpinning of critical thinking. I describe this moral underpinning as a sense of striving toward the greater good; an ambiguous outcome perhaps, which we don't have time to explore herein, but a clear moral component nonetheless. Critical thinking, "distinguished from being "critical of ideas" in the sense of being harsh (or) negative" (Facione, 1984: p. 255), is actually a positive activity that seeks to ascertain truth and fact for the greater good.

Paul's conception of strong sense critical thought (Paul \& Binkler, 1990) is underpinned by his concerns about weak sense critical thinking. Herein, critical thinking may seem to be engaged on a surface level but can actually ensue in the sophistry mentioned above, and a perpetuation of unquestioned and homogenised thinking in a manner that hijacks the real nature and intention of critical thinking. Paul's conception of weak sense critical thinking can be "understood as a set of discrete micro-logical skills extrinsic to the character of the person" (Paul \& Binkler, 1990: p. 162-163). Weak sense critical thinking runs the risk of becoming self-interested because students become "more skilled in "rationalizing" and "intellectualizing" the biases they already have" (Paul, 1982: p. 3). Since "sometimes reasoning is explicitly cast into the form of an argument and sometimes it is not" (Paul, 1982: p. 4), it is easy to over simplify the processes of critical thinking and abuse the logical reasoning involved. This is why "reasoning is a broader concept, all critical thinking is good reasoning, but not all good reasoning is critical thinking" (Facione, 1984: p. 255). It is possible to site reasons, even seemingly complex ones, without being genuinely engaged in critical thought. Critical thinking goes beyond mere reasoning to concern reasoning motivated toward a common good, that is to say, interests beyond the individual's, and is thus 
performed in a reflective, metacognitive, self-regulatory and honest manner.

Mason (2007) summarizes theorists to inform that "critical thinking is principled thinking, at least in terms of the principles of impartiality, consistency, non-arbitrariness and fairness" (Mason, 2007: p. 342). In this way, reflection goes beyond ensuring we are critically aware of our own perceptions, by implying a moral obligation to critically examine multiple perspectives in the aim of fairness, thus reasserting the way critical thinkers strive for positive ends by prioritizing this over valuing their own view ipso facto. Mason (2007: p. 343) finds some consensus among different philosophers of education that dispositions of critical thinking comprise a "critical attitude" and a "moral dimension". Such that critical thinkers are motivated by the truth, not only for its own sake, but also because of they are interested in societal benefit.

Coupled with self-reflection, a desire to seek productive ends is of key importance since it is this disposition that ensures we persevere in the responsible manner that ensures our own beliefs are not valued for their own sake, but are critically examined in the same manner as others. Reflection and a motivation toward the truth and productive ends are of the utmost importance in ensuring critical thinking is not practised in a weak, potentially self-serving or reductive, manner. Critical thinking thus demands "perseverance, integrity and responsibility" (The Center for Critical Thinking, 2013).

\section{Implications for Critical Pedagogy}

The critical faculty is a product of education and training. It is a mental habit and power. It is a prime condition of human welfare... (Sumner, 1909: p. 1564).

Critical thinking, understood as encompassing the four features described: logical reasoning, reflection, an awareness of power relationships and a striving toward the greater good, has implications for the goals that motivate teachers' pedagogical practice. Through the work of critical theorists, we learn that whist we attribute views and choices to individuals, the motivations behind our values and actionsare not necessarily those of transcendent, free subjects. For example, Bourdieu's (1980) conception of the habitus, a label given to predispositions toward thought and action instilled in us by our context, and Foucault's (1972-7) influential work which depicts a subject similarly constituted by the world him/her, we are reminded that our thinking is readily conditioned by cultural, political and economic fields. These philosophical concerns around agency help exemplify the importance of critical thinking, motivating the critical teacher to contribute to the development of thinking skills that help alleviate social conditioning and increase autonomy.

Understanding that critical thinking involves a capacity and willingness to reflect on issues associated with power, and that it has a moral underpinning, means that the development of critical thinking in students has implications for their agency. In accordance with its use in literature in the area of critical thinking, a liberal education can refer to educational practice that is transformative, emancipatory and empowering. This understanding underpins significant educational philosophy in the 21st century (Association of American Colleges \& Universities, 2015). The paramount place of critical thinking in striving toward a liberal education that recognises the inherency of thinking in learning is well established. In UNESCO's educational Implementation Guide, Teaching respect for all, they acknowledge that "a fundamental commitment to creating an emancipatory culture of schooling that empowers (minority) students" demands "education that focuses on critical thinking" (2014: p. 35). Lipman (1988: p. 42) also acknowledges "the promise of intellectual empowerment" derived from "the gradual shift... in the focus of education - the shift from learning to thinking". Further insight into these educational endeavours is afforded through philosophical perspectives that acknowledge the constructed nature of our thinking mentioned and the subsequent opportunity for education to increase students' potential to think autonomously (Bourdieu, 1977, 1980; Swartz, 1997). In this way, a philosophical understanding of the power structures at play in the production of our thinking skills, tendencies and dispositions, provides further support for the perceived value of education as a potentially liberating force and the role of critical thinking in a kind of social emancipation; a kind of freedom that entails greater conscious awareness of power relationships on the formation of students' thinking and their capacity to independently reflect on and monitor their thinking. Facione recognises critical thinking "as a liberating force in education and a powerful resource in one's personal and civic life" (Facione et al., 1990: p. 2) because it encourages a sceptical outlook and analytic ability to critically discern, interpret and act on information in an autonomous manner. It is a "powerful resource" in our personal and social lives because it impacts positively on our intrapersonal intelligence, interpretation and assessment of information, relationships and experiences. It helps us to solve problems and think ahead. And the dispositions it fosters 
prompt concern for progress, open mindedness and civic engagement. Critical thinking is thus paramount in a liberal education (Facione, 1990).

In Paul and Binklers' work they lament a lack of dialogical, dialectical and reassured empathetic thought (Paul \& Binkler, 1990), that means cultural structures, divides and powers that pre-exist us, influence (at best) or determine (at worst) the construction of our views and values, allowing social divides to be reinforced and the world's most significant barriers to peace to go unchecked. Paul (1990: p. 167) observes that a lack of genuine critical thought undermines our need for "emancipatory reason". Paul (1982) comments on the liberating potential of critical thinking since his strong sense understanding emphasises not only a deep knowledge of oneself, but an ability to appreciate ideas more holistically; understanding contrasting worldviews and how these are influenced by particular backgrounds so that an individual thinker can orient themselves within this broad context. Paul makes the following observations to highlight an appropriate pedagogical approach that emphasises a global outlook, to be one that helps students identify the (power) relationship between themselves and social fields, and that highlights the significance of the way that power is manifested implicitly:

By introducing the student from the outset to these more "global" problems in the analysis and evaluation of reasoning, we can, indeed must if we are to be successful, help him or her to a clearer theoretical recognition of the relationship between world views, forms of life, human engagements and interests, what is at stake (in contrast to what is at issue), how what is at issue is often itself the issue, how the unexpressed as well as the expressed may be significant, of the difficulties as a result of the above, in judging credibility, and, last but not least, of the ethical dimension in most important and complex human problems (Paul, 1982: p. 3).

It is the conscious awareness of what is "unexpressed as well as the expressed" that requires critical reflection on our social setting and the relationships comprised that impact our thinking. This ability to think critically about our predispositions for thought, and relationships at play in their construction, underpins Paul'sstrong sense conception (Paul, 1982: p. 3). Paul's (1982: p. 4) "basic theoretical underpinnings for a strong sense approach include his acknowledgement that "as humans we are - first, last and always - engaged in inter-related life projects which, taken as a whole, define our personal "form of life" in relation to broader "social" forms", social forms Bourdieu may compare to fields.

Critical thinking skills are imperative for individuals for the sake of individual autonomy and the ability to more independently structure and evaluate our thinking, beliefs and attitudes in relation to their constructed nature, power relationships within society and the impact of one's views on others. Given the acknowledgement that critical thinking skills enhance intellectual freedom in this manner, it is no surprise that a liberal education is almost synonymous with an education that develops independent, critical thinkers.

\section{Conclusion: Clarifying a Communicable Understanding}

I have sought to identify four key features of critical thinking that draw together threads of research in this area for clarification for teachers. These four features comprise skills and dispositions required to operate in combination to achieve critical thought. In light of their importance, and complex and challenging nature, I have called them formidable. In a first step to help develop critical thinking in students, we must respect each feature involved and clarify our own understanding (Table 1).

How teachers might endeavor to develop students capable of and willing to engage in critical thinking is of the utmost importance. But starting the process with a clear understanding of the nature of their goal, however formidable, is imperative to improve the teacher's own critical thought and inform the pedagogical approaches they adopt to inspire their students.

\section{Acknowledgements}

Thanks to my supervisors, Dr. David Zyngier and Dr. Nathan Brubaker.

\section{References}

Association of American Colleges \& Universities (2015). What Is a 21st Century Liberal Education? http://www.aacu.org/leap/what-is-a-liberal-education 
Bassham, G., Irwin, W., Nardone, H., \& Wallace, J. (2005). Critical Thinking: A Student's Introduction. Massachusetts: McGraw Hill.

Bloom, B. S. (1956). Taxonomy of Educational Objectives, the Classification of Educational Goals-Handbook 1: Cognitive Domain. New York: McKay.

Bourdieu, P. (1977). Outline of a Theory of Practice. London: Cambridge University Press. http://dx.doi.org/10.1017/CBO9780511812507

Bourdieu, P. (1980). Questions de Sociologie. Paris: Editions de Minuit.

Ennis, R. (1996). Critical Thinking. New Jersey: Prentice-Hall.

Facione, P. (2013). Critical Thinking: What It Is and Why It Counts. The California Academic Press. http://www.insightassessment.com/CT-Resources/Critical-Thinking-What-It-Is-and-Why-It-Counts

Facione. P. (1990). The Delphi Report: Executive Summary; Critical thinking: A Statement of Expert Consensus for Purposes of Educational Assessment and Instruction. California: The California Academic Press.

Facione. P., Sanchez, C. A., Facione, N. C., \& Gainen, J. (1995). The Disposition toward Critical Thinking. The Journal of General Education, 44, 1-25.

Foucault, J. (1972-7). Power/Knowledge: Selected Interviews and Other Writings 1972-1977. In C. Gordon (Ed.). New York: Pantheon Books.

Lipman, M. (1984). The Cultivation of Reasoning through Philosophy. Educational Leadership, 42, 51-56.

Lipman, M. (1988). Critical Thinking-What Can It Be? Educational Leadership, 46, 38-44.

Mason, M. (2007). Critical Thinking and Learning. Educational Philosophy and Theory, 39, 339-349. http://dx.doi.org/10.1111/j.1469-5812.2007.00343.x

Mill, J. S. (1873). Moral Influences in Early Youth. My Father's Character and Opinions. In J. S. Mill (Ed.), Autobiography (iBook) (pp. 52-85). London: Longmans, Green, Reader and Dyer.

Paul, R. (1982). Critical Thinking in the 'Strong' Sense: A Focus on Self-Deception, World Views, and a Dialectical Mode of Analysis. http://www.criticalthinking.org/data/pages/99/579d6b9722ed3418d0b4a7514f0a9f1d513655794857b.pdf

Paul, R. W., \& Binkler, J. A. (1990). Critical Thinking: What Every Person Needs to Survive in a Rapidly Changing World. Rohnert Park, CA: Center for Critical Thinking and Moral Critique.

Robinson, R. S. (2011). Teaching Logic and Teaching Critical Thinking: Revisiting McPeck. Higher Education Research \& Development, 30, 275-287. http://dx.doi.org/10.1080/07294360.2010.500656

Ruminski, H. J., \& Hanks, W. E. (1995). Critical Thinking Lacks Definition and Uniform Evaluation Criteria. Journalism \& Mass Communication Educator, 50, 4-11. http://dx.doi.org/10.1177/107769589505000302

Sumner, W. G. (1906). Education, History. In W. G. Sumner (Ed.), Folkways: A Study of the Sociological Importance of Usages, Manners Customs, Mores, and Morals (iBook) (pp. 1553-1578). Boston, MA: The Athenaeum Press.

Swartz, D. (1997). Culture and Power: The Sociology of Pierre Bourdieu. Chicago: The University of Chicago Press.

The Center for Critical Thinking (2013). Our Mission. http://www.criticalthinking.org/pages/our-mission/405

Verlinden, J. (2005). Critical Thinking and Everyday Argument. Belmont, CA: Wadsworth. 